\title{
ANALISIS PENGARUH KARAKTERISTIK INDIVIDU TERHADAP PRESTASI KERJA \\ (STUDI PADA PEGAWAI POLITEKNIK ILMU PELAYARAN SEMARANG)
}

\author{
Firdaus Sitepu ${ }^{a}$, Janny Adriani Djari ${ }^{\text {b }}$ \\ a dan b Dosen Program Studi Nautika PIP Semarang
}

\begin{abstract}
This research aim to know individual characteristic influence to labour capacity Politeknik Ilmu Pelayaran Semarang. Research regarding do individual characteristic influence intervening motivation and work characteristic to labour capacity take population officer of Politeknik Ilmu Pelayaran Semarang amounting to 218 people. Intake of sample with sampling random technique representing technique intake of sample at random with determination of is amount of sampel used by slovin formula obtained by 142 responder. As for data obtained with kuesioner with data analysis use linear regression.

Pursuant to research which have been done by hence can be obtained by the following conclusion is existence of positive influence and signifikan between individual characteristic to labour capacity.
\end{abstract}

\section{Keyword : Individual Characteristic and labour capacity}

\section{PENDAHULUAN}

Salah satu faktor yang mempengaruhi peningkatan prestasi kerja pegawai dalam suatu organisasi adalah karakteristik individu pegawai (person characteristic) yang terdiri dari pengetahuan, pengalaman kerja, kemampuan dan keterampilan, sikap dan motivasi. Karakteristik individu merupakan perbedaan dari masing-masing pegawai yang dapat mempengaruhi dalam berperilaku dan melakukan suatu pekerjaan (Sedarmayanti, 2009). Dengan mengetahui perbedaan karakter individu, para manajer akan dapat menentukan tugas-tugas yang sesuai dengan karakternya sehingga peningkatan prestasi kerja akan dapat dicapai. Karakteristik individu sangat menunjang seseorang dalam melaksanakan pekerjaan dan akan memberikan kontribusi positif terhadap keberhasilan prestasi kerja pegawai

Penelitian mengenai pengaruh karakteristik individu terhadap prestasi kerja pegawai pernah dilakukan oleh Cholifah Noor (2012) serta Riska Yunita, Paranoan dan Gunthar Riady (2014) yang menghasilkan karakteristik individu berpengaruh positif dan signifikan terhadap kinerja pegawai. Berbeda hasil penelitian yang dilakukan oleh Mohammad Sapta
Heriyawan (2014) dan Destia Aktarina (2015) yang menghasilkan karakteristik individu tidak berpengaruh signifikan terhadap prestasi kerja.

Kajian penelitian mengenai pengaruh karakteristik individu terhadap prestasi kerja pegawai akan dilakukan pada pegawai Politeknik Ilmu Pelayaran Semarang. Politeknik Ilmu Pelayaran Semarang adalah salah satu Lembaga Pendidikan Maritim negeri dibawah naungan Kementerian Perhubungan dan satu-satunya yang berada di Jawa Tengah, yang berlokasi di Jalan Singosari 2A Semarang dengan tugas pokok membina dan mencetak lulusan perwiraperwira kapal niaga, baik kapal-kapal milik Negara maupun kapal-kapal swasta.

Berdasarkan latar belakang tersebut di atas, maka peneliti akan menguji tentang pengaruh karakteristik individu terhadap prestasi kerja pegawai (Studi pada Pegawai Politeknik Ilmu Pelayaran Semarang).

Berdasarkan hal tersebut, maka timbul pertanyaan dalam penelitian ini adalah sebagai berikut: "Apakah karakteristik individu berpengaruh terhadap prestasi kerja pegawai Politeknik Ilmu Pelayaran Semarang?" 
Firdaus Sitepu ${ }^{\mathrm{a}}$, Janny Adriani Djari ${ }^{\mathrm{b}}$

Adapun tujuan penelitian ini adalah:

1. Untuk menganalisis pengaruh karakteristik individu terhadap prestasi kerja pegawai Politeknik Ilmu Pelayaran Semarang"

2. Pihak yang berkepentingan dalam rangka mengambil kebijakan yang berkaitan dengan karakteristik individu dikaitkan dengan prestasi kerja pegawai.

3. Sebagai masukan bagi penelitian selanjutnya dalam mengembangkan penelitian mengenai karakteristik individu dikaitkan dengan prestasi kerja pegawai.
Hal yang penting dalam pengelolaan sumber daya manusia adalah mengenai prestasi kerja pegawai. Prestasi kerja pegawai sebagai hasil kerja secara kualitas dan kuantitas yang dapat dicapai oleh seseorang pegawai dalam melaksanakan tugas sesuai dengan tanggung jawab yang diberikan kepadanya. Hal yang mendukung prestasi kerja pegawai tersebut adalah karakteristik individu. Berdasarkan uraian tersebut diatas maka dapat disusun kerangka teoritis sebagai berikut:

\section{Kerangka Penelitian}

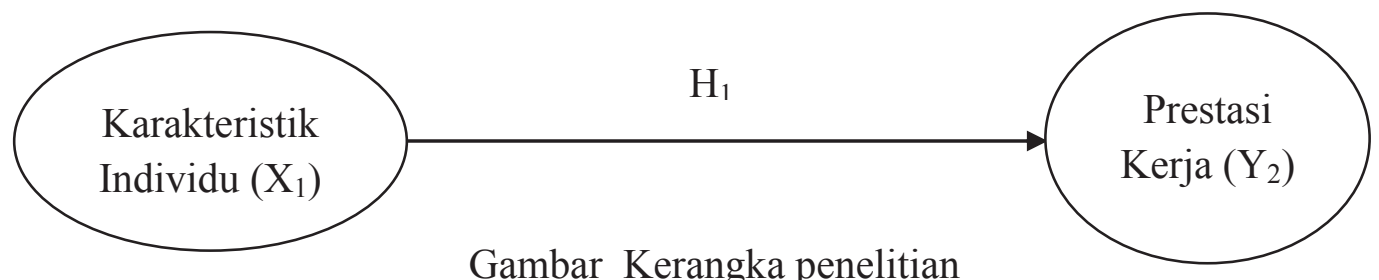

Gambar Kerangka penelitian

\section{METODE PENELITIAN}

\section{Populasi Penelitian}

Populasi menurut Sutrisno Hadi (2006) adalah sekumpulan dari seluruh elemenelemen yang dalam hal ini diartikan sebagai obyek penelitian. Adapun populasi dalam penelitian ini adalah pegawai Politeknik Ilmu Pelayaran Semarang yang berjumlah 218 orang.

\section{Sampel Penelitian}

Sampel adalah sebagian atau wakil populasi yang akan diteliti (Sutrisno Hadi, 2006). Sampel dalam penelitian ini adalah pegawai Politeknik Ilmu Pelayaran Semarang. Pengambilan sampel dengan teknik random sampling yang merupakan teknik pengambilan sampel secara acak. Untuk penentuan jumlah sampel berdasarkan pendapat Umar (2009) yang menyatakan jumlah sampel minimal 30 pada kebanyakan penelitian sudah terwakili. Oleh sebab itu penentuan jumlah sampel digunakan rumus slovin dihasilkan sebesar 142 responden

Definisi Konsep, Operasional Dan Pengukuran Variabel Tabel Definisi Konsep, Operasional dan Pengukuran Variabel

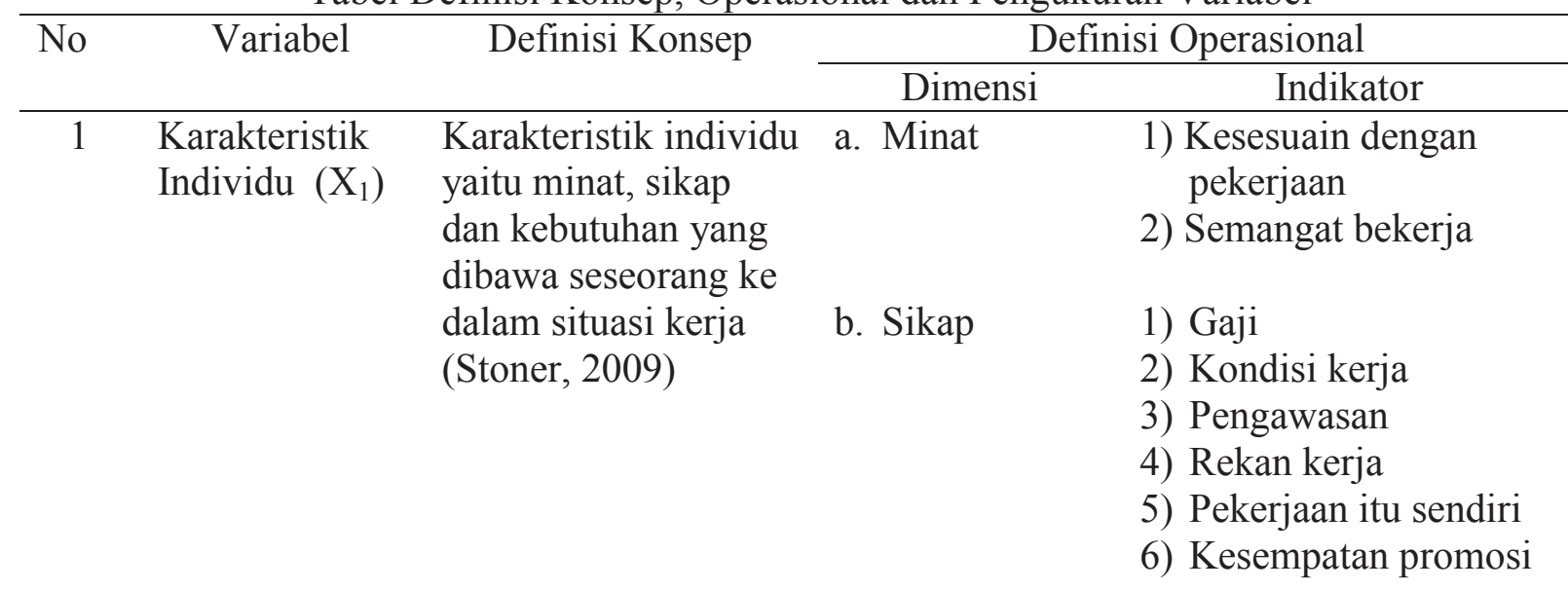




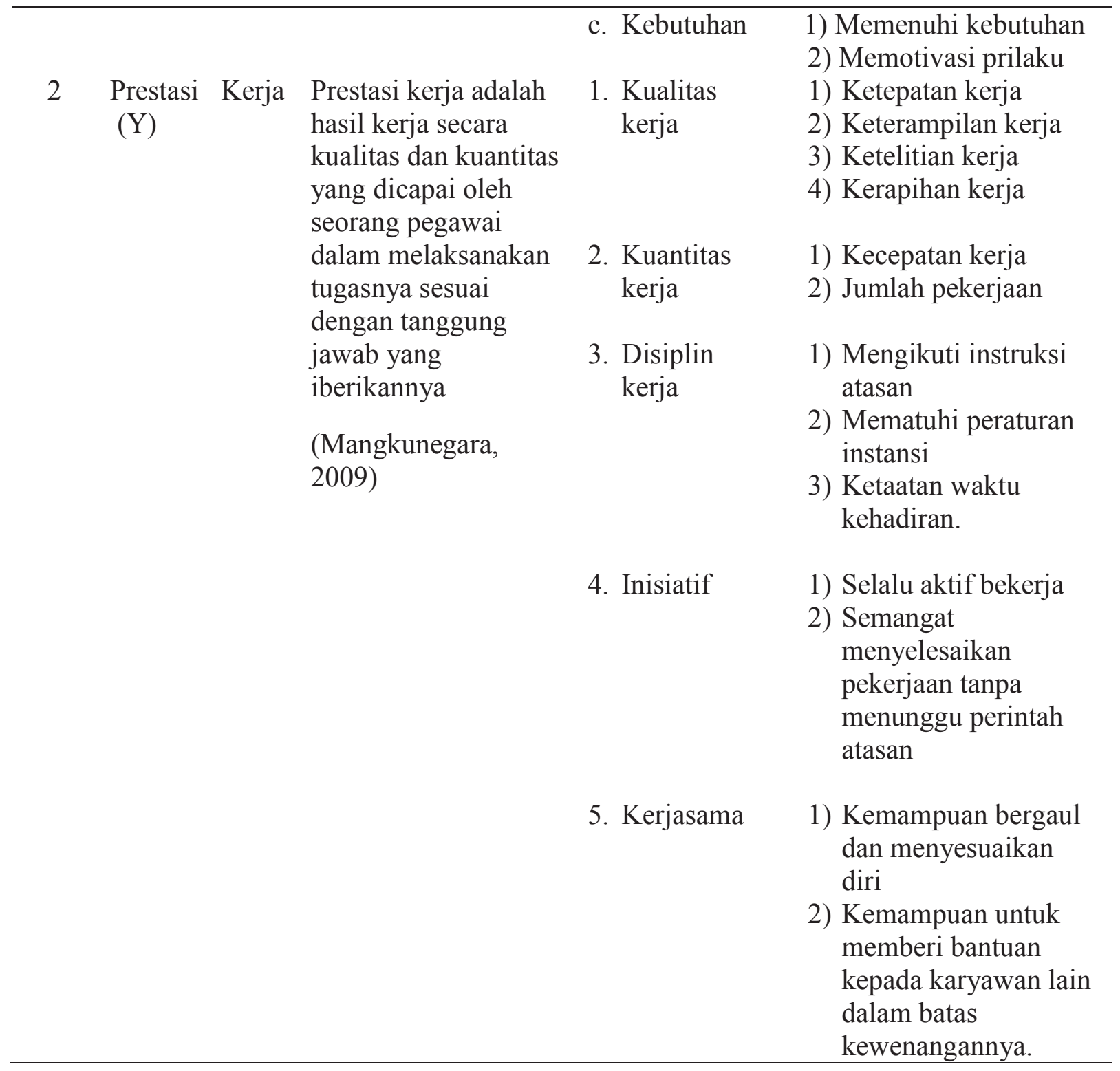

\section{Jenis dan Sumber Data}

Dalam penelitian ini menggunakan data primer. Data primer merupakan dataa yang bersumber dari tangan pertama, dataa yang diambil menggunakan cara kuesioner. Kuesioner merupakan daftar pertanyaan yang dipakai sebagai pedoman untukk mengadakan tanya jawab dengan responden mengenai pengaruh karakteristik individu dan karakteristik pekerjaan terhadap prestasi kerja pegawai.

\section{Uji Instrumen Penelitian}

a. Uji Validitas

Uji validitas digunakan untuk mengukur valid tidaknya suatu indikator yang berbentuk kuesioner. Suatu kuesioner dikatakan valid jika pertanyaan mampu untuk mengungkapkan suatu yang akan diukur oleh kuesioner tersebut. Dalam penelitian ini, uji validitas menggunakan analisis faktor yaitu dengan menguji apakah butir-butir indikator atau kuesioner yang digunakan dapat mengkonfirmasikan sebuah faktor atau konstruk. Jika masingmasing pertanyaan merupakan indikator pengukur maka memiliki KMO diatas 0,5 dan signifikansi dibawah 0,05 serta memiliki nilai kriteria loading faktor pengujian sebagai berikut (Ghozali, 2006):

- Loading faktor > rule of tumb $(0,4)$ berarti valid

- Loading faktor < rule of tumb $(0,4)$ berarti tidak valid

b. Uji Reliabilitas 
Firdaus Sitepu ${ }^{\mathrm{a}}$, Janny Adriani Djari ${ }^{\mathrm{b}}$

Suatu alat ukur instrumen disebut reliabel, jika alat tersebut dalam mengukur segala sesuatu pada waktu berlainan, menunjukkan hasil yang relatif sama. Pengukuran reliabilitas dapat dilakukan dengan koefisien Alpha Cronbach menggunakan SPSS For Windows (Ghozali, 2006) dengan kriteria :

- Bila nilai alpha > 0,7 maka instrumen reliabel

- Bila nilai alpha $<0,7$ maka instrumen tidak reliabel

\section{Analisis Regresi Berganda}

Suatu analisa yang digunakan untuk mengetahui persamaan regresi yang menunjukkan persamaan antara variabel dependent dan variabel independent dengan rumus sebagai berikut:

$\mathrm{Y}_{1}=\mathrm{a}+\beta_{1} \mathrm{X}_{1}+\mathrm{e}$

Keterangan:

a $=$ Konstanta

$\mathrm{Y} \quad=$ Prestasi Kerja

$\mathrm{X}_{1}=$ Karakteristik Individu

$\beta=$ Koefisien regresi

$\mathrm{e} \quad=$ Error

\section{Uji Goodness of Fit (Uji Model)}

a. Koefisien determinasi

Koefisien Determinasi (Goodness of fit), yang dinotasikan dengan $\mathrm{R}^{2}$ merupakan suatu ukuran yang penting dalam regresi. Determinasi $\left(\mathrm{R}^{2}\right)$ mencerminkan kemampuan variabel dependen. Tujuan analisis ini adalah untuk menghitung besarnya pengaruh variabel independen terhadap variabel dependen. Nilai $\mathrm{R}^{2}$ menunjukkan seberapa besar proporsi dari total variasi variabel tidak bebas yang dapat dijelaskan oleh variabel penjelasnya. Semakin tinggi nilai $\mathrm{R}^{2}$ maka semakin besar proporsi dari total variasi variabel dependen yang dapat dijelaskan oleh variabel independen (Ghozali, 2006).

b. Uji Signifikan F
Uji signifikan yaitu untuk mengidentifikasi pengaruh variabel independen terhadap variabel dependen dengan menggunakan SPSS (Ghozali, 2006). Adapun kriterianya apabila taraf signifikan $(\alpha)<0,05$.

Pengambilan keputusan:
a Jika tingkat signifikan $<0,05$, maka seluruh variabel independen berpengaruh signifikan terhadap variabel dependen
b Jika tingkat signifikan $>0,05$, maka seluruh variabel independen tidak berpengaruh signifikan terhadap variabel dependen

\section{Uji Hipotesis}

Uji hipotesis menggunakan uji parsial (uji t) dengan model regresi linier berganda yaitu untuk mengidentifikasi pengaruh variabel independent terhadap variabel dependent secara parsial dengan menggunakan SPSS (Ghozali, 2006). Adapun kriteria hipotesis diterima bila taraf signifikan $(\alpha)<0,05$. Hipotesis yang diajukan sebagai berikut:

Ho : $\beta=0$, Artinya tidak terdapat pengaruh signifikan antara variabel independen terhadap variabel dependen secara parsial

Ha : $\beta \neq 0$, Artinya terdapat pengaruh signifikan antara variabel independen terhadap variabel dependen secara parsial

Pengambilan keputusan:

a. Jika tingkat signifikan $<0,05$, maka seluruh variabel independen secara parsial (individual) berpengaruh signifikan terhadap variabel dependen

b. Jika tingkat signifikan $>0,05$, maka seluruh variabel independen secara parsial (individual) tidak berpengaruh signifikan terhadap variabel dependen

\section{HASIL DAN DISKUSI}

Pengujian tahap ini digunakan untuk mengetahui pengaruh karakteristik individu terhadap prestasi kerja: 
Tabel Hasil Regresi Persamaan Pengaruh $\quad \mathrm{Y}_{2}=0,646$ X1

karakteristik individu terhadap prestasi kerja Berdasarkan persamaan tersebut dapat

\begin{tabular}{|c|c|c|c|c|c|}
\hline \multirow[t]{2}{*}{ Model } & \multicolumn{2}{|c|}{$\begin{array}{l}\text { Unstandardized } \\
\text { Coefficients }\end{array}$} & $\begin{array}{l}\text { Standar- } \\
\text { dized } \\
\text { Coeffi- } \\
\text { cients }\end{array}$ & \multirow[t]{2}{*}{$\mathrm{T}$} & \multirow[t]{2}{*}{ Sig. } \\
\hline & B & $\begin{array}{l}\text { Std. } \\
\text { Error }\end{array}$ & Beta & & \\
\hline 1 (Constant) & -28.875 & 4.647 & & -6.213 & .000 \\
\hline $\begin{array}{l}\text { Karakteristik } \\
\text { Individu }\end{array}$ & 1.000 & .068. & .646 & 14.761 & .000 \\
\hline
\end{tabular}
diketahui hasil hipotesis:

Hasil koefisien regresi karakteristik individu 0,646 dan nilai signifikan sebesar $0,000<0,05$. Berdasarkan hasil pengujian dapat disimpulkan bahwa pengujian tersebut mampu menerima $\mathbf{H}_{1}$, sehingga dugaan adanya pengaruh antara karakteristik individu terhadap prestasi kerja terbukti atau dapat diterima.

a. Dependent Variable: Prestasi Kerja

Sumber: data primer yang diolah, 2016

\section{Analisis Koefisien Determinasi}

Pada tabel di atas hasil analisis regresi persamaan II pengaruh karakteristik individu dan karakteristik pekerjaan terhadap prestasi kerja dengan motivasi sebagai variabel intervening dapat diketahui persamaan regresi sebagai berikut:

Analisis koefisien determinasi digunakan untuk mengukur seberapa jauh kemampuan model dalam menerangkan variasi variabel dependen, dimana ditunjukkan dengan nilai Adjusted $R$ Square. Berikut hasil pengujian yang dibantu dengan program SPSS sebagai berikut:

Tabel Koefisien Determinasi Persamaan

Pengaruh karakteristik individu terhadap prestasi kerja

Model Summary

\begin{tabular}{lrrrr}
\hline Model & R & R Square & $\begin{array}{c}\text { Adjusted R } \\
\text { Square }\end{array}$ & $\begin{array}{l}\text { Std. Error of } \\
\text { the Estimate }\end{array}$ \\
\hline 1 & $.921^{\mathrm{a}}$ & .849 & .845 & 5.033 \\
\hline $\begin{array}{l}\text { a. Predictors: (Constant), Karakteristik Pekerjaan, Karakteristik } \\
\text { Individu }\end{array}$
\end{tabular}

Sumber: data primer yang diolah, 2016

Berdasarkan tabel di atas menunjukkan bahwa besarnya prosentase variabel prestasi keja mampu dijelaskan oleh variabel karakteristik individu ditunjukkan dengan nilai $R$ Square $\left(\mathrm{R}^{2}\right)$ yaitu sebesar 0,849 . Dipilihnya $R$ Square agar data tidak bias terhadap jumlah variabel independen yang dimasukkan ke dalam model. Setiap tambahan satu variabel independen, maka $R$ square pasti meningkat tidak perduli apakah variabel tersebut berpengaruh secara signifikan terhadap variabel dependen. Dalam hal ini dapat diartikan bahwa prestasi kerja mampu dijelaskan oleh variabel karakteristik individu dengan nilai sebesar $84,9 \%$, sedangkan sisanya sebesar $15,1 \%$ dari $(100 \%$ - 84,9\%) dijelaskan oleh variabel lain yang tidak diteliti dalam penelitian ini.

Uji F digunakan untuk mengidentifikasi pengaruh variabel independen terhadap variabel dependen secara bersama-sama dan dapat juga untuk menunjukkan kelayakan model persamaan regresi. 
Analisis Pengaruh Karakteristik Individu terhadap Prestasi Kerja (Studi pada Pegawai Politeknik Ilmu Pelayaran Semarang)

Firdaus Sitepu ${ }^{\mathrm{a}}$, Janny Adriani Djari ${ }^{\mathrm{b}}$

Tabel Hasil Pengujian Model (Uji F) Persamaan

Pengaruh karakteristik individu terhadap prestasi kerja

\begin{tabular}{rlrrrrr}
\multicolumn{8}{c}{ ANOVA $^{\mathbf{b}}$} \\
\hline & Model & Sum of Squares & Df & Mean Square & \multicolumn{1}{c}{ F } & \multicolumn{1}{c}{ Sig. } \\
\hline \multirow{2}{*}{1} & Regression & 19580.033 & 3 & 6526.678 & 257.643 & $.000^{\mathrm{a}}$ \\
& Residual & 3495.854 & 138 & 25.332 & & \\
& Total & 23075.887 & 141 & & & \\
\hline
\end{tabular}

a. Predictors: (Constant), Karakteristik Individu

b. Dependent Variable: Prestasi Kerja

Sumber: Data primer yang diolah, 2016

Berdasarkan tabel di atas hasil pengujian model (Uji F) pengaruh variabel karakteristik individu terhadap prestasi kerja dapat diketahui hasil $\mathrm{F}$ hitung 257,643 dan tingkat signifikan $0,000<0,05$ sehingga dapat dikatakan bahwa ada pengaruh antara variabel karakteristik individu terhadap prestasi kerja dan regresi tersebut layak digunakan dalam penelitian.

\section{Pembahasan}

Hasil penelitian yang dilakukan untuk mengetahui pengaruh karakteristik individu terhadap prestasi kerja pada pegawai Politeknik Ilmu Pelayaran Semarang adalah sebagai berikut :

Hasil koefisien regresi karakteristik individu 1,000 dan nilai signifikan sebesar $0,000<0,05$. Berdasarkan hasil pengujian dapat disimpulkan bahwa pengujian tersebut mampu menerima $\mathrm{H}_{1}$, sehingga dugaan adanya pengaruh antara karakteristik individu terhadap prestasi kerja terbukti atau dapat diterima. Hasil penelitian ini sama dengan penelitian terdahulu yang dilakukan oleh Cholifah Noor (2012) serta Riska Yunita, Paranoan dan Gunthar Riady (2014) yang menghasilkan karakteristik individu berpengaruh positif dan signifikan terhadap prestasi kerja pegawai.

Karakteristik individu merupakan perbedaan dari masing-masing pegawai yang dapat mempengaruhi dalam berperilaku dan melakukan suatu pekerjaan (Sedarmayanti, 2009). Dengan mengetahui perbedaan karakter individu, para manajer akan dapat menentukan tugas-tugas yang sesuai dengan karakternya sehingga peningkatan prestasi kerja akan dapat dicapai. Karakteristik individu sangat menunjang seseorang dalam melaksanakan pekerjaan dan akan memberikan kontribusi positif terhadap keberhasilan prestasi kerja pegawai

\section{KESIMPULAN}

Berdasarkan penelitian mengenai pengaruh karakteristik individu terhadap prestasi kerja pada pegawai Politeknik Ilmu Pelayaran Semarang dapat diperoleh kesimpulan sebagai berikut : Karakteristik individu berpengaruh positif dan segnifikan terhadap prestasi kerja. Dengan demikian semakin tepat karakteristik individu pada pekerjaannya, maka akan dapat meningkatkan prestasi kerja pegawai.

\section{DAFTAR PUSTAKA}

Arifin, Noor. 2012. Analisis Kualitas Kehidupan Kerja, Kinerja, dan Kepuasan Kerja Pada CV. Duta Senenan Jepara. Jurnal Economia, Volume 8, Nomor 1, April 2012

Dessler, Gary. 2000. Manajemen Personalia Teknik dan Konsep Modern. Alih Bahasa: Agus Dharma. Edisi Ketiga. Jakarta : Penerbit Erlangga

Ghozali, Imam. 2006. Aplikasi Analisis Multivariate dengan Program SPSS. Semarang: Badan Penerbit Universitas Diponegoro 
Hadi, Sutrisno. 2006. Metode Penelitian Riset. Yogyakarta: Yayasan Penerbit Fakultas Biologi UGM

Hasibuan, S.P. Malayu. 2009. Organisasi dan Motivasi. Jakarta: PT. Bumi Aksara

Mangkunegara, Anwar Prabu. 2009. Perilaku dan Budaya Organisasi. Bandung : Penerbit Refika Aditama

Maryoto. 2000. Manajemen Sumber Daya Manusia (Manajemen Kepegawaian). Cetakan ke 8. Bandung: Mandar Maju

Maslow, Abraham H. 1954. Motivation And Personality. New York: Harper \& Row Publiser

Munandar. 2012. Manajemen Sumber Daya Manusia. Jurnal Manajemen Desember 2007
Notoatmojo, K. 2009. Manajemen Sumber Daya Manusia. Jakarta : Bima Aksara

Robbins, S. P. 2002. Prinsip-Prinsip Perilaku Organisasi (Alih Bahasa oleh Halida dan Dewi Sartika). Edisi Kelima. Jakarta : Erlangga

Simamora, Henry. 2004. Sumber Daya Manusia. Yogyakarta: STIE

Suprihantono. 2008. Pengaruh Kompensasi dan Karakteristik Pekerjaan Terhadap Kepuasan Kerja, Wacana, Vol. 4 No. 1 Juli 2000. Surabaya

Tella, Adeyinka. 2007. Work Motivation, Job Satisfation and Organisational Commmitment of Library Personnel in Academic and Research Libraries in Oyo State. Nigeria: Library Philosopy and Practice 